\title{
Anabases
}

ANABASES Traditions et réceptions de l'Antiquité

$3 \mid 2006$

Varia

\section{Daphné GONDICAS, Jeannine BOËLDIEU-TRÉVET, Lire}

Hérodote

Pascal Payen

\section{OpenEdition}

\section{Journals}

Édition électronique

URL : http://journals.openedition.org/anabases/2635

DOI : 10.4000/anabases.2635

ISSN : 2256-9421

\section{Éditeur}

E.R.A.S.M.E.

Édition imprimée

Date de publication : 1 mars 2006

Pagination : 284-286

ISSN : 1774-4296

\section{Référence électronique}

Pascal Payen, « Daphné gondicas, Jeannine boËLdieu-trévet, Lire Hérodote », Anabases [En ligne], 3 | 2006 , mis en ligne le 01 janvier 2012, consulté le 22 septembre 2020. URL : http://journals.openedition.org/ anabases/2635; DOI : https://doi.org/10.4000/anabases.2635

Ce document a été généré automatiquement le 22 septembre 2020.

(c) Anabases 


\title{
Daphné GONDICAS, Jeannine BOËLDIEU- TRÉVET, Lire Hérodote
}

\author{
Pascal Payen
}

\section{RÉFÉRENCE}

Daphné GONDICAS, Jeannine BOËLDIEU-TRÉVET, Lire Hérodote, Paris, Bréal, coll. «Sources

d'histoire», 2005, $320 \mathrm{p}$.

15 euros / ISBN 2-7495-0343-4

1 Les livres consacrées depuis les dernières décennies à Hérodote et à son Enquête sur des thèmes particuliers ainsi que les synthèses plus générales paraissent à un rythme très régulier : qu'il suffise de rappeler, parmi d'autres, le récent Brill's Companion to Herodotus (2002), et les ouvrages de John Gould (Herodotus, 1989), de James Romm (Herodotus, 1998), de Reinhold Bichler et Robert Rollinger (Herodot, 2000). Aucun, cependant, ne présente une synthèse aussi ouverte à tous les courants des recherches récentes que le livre de Daphné Gondicas et Jeannine Boëldieu-Trévet, Lire Hérodote.

2 Pour rendre compte du projet de ce Grec d'Asie Mineure "de rendre visible et intelligible [le] monde » dans lequel il vécut et voyagea, les auteurs font le point en cinq parties équilibrées sur tous les aspects de l'œuvre et s'appuient sur les perspectives anciennes et nouvelles de la recherche, sans jargon, en offrant autant de points de vue pour analyser une source essentielle sur les mondes grecs et barbares. La première partie rappelle les données d'ordre biographique et surtout expose les principes et l'épistémologie de l'enquête, son objet et sa méthode fondée sur l'exercice de la "vue » (opsis), de l'« ouïe » (akoè) et du « jugement " (gnômè). La deuxième partie fait droit à un Hérodote ethnographe et anthropologue dans sa manière de "voir le monde», de décrire les coutumes, les espaces et les peuples, le plus souvent lorsque se présente la menace d'une guerre ou d'une conquête. Dans la structure du récit et dans la réflexion de l'enquêteur, les rapports entre Grecs et Barbares reposent ainsi tantôt sur l'analogie, tantôt sur la différence, mais à partir d'une grille d'observation dont les rubriques se 
retrouvent pour tous, dans la diversité de leurs genres de vie, de leurs pratiques alimentaires, sexuelles, matrimoniales, de leurs croyances religieuses, de leurs rites funéraires. Cette riche matière est ordonnée dans un récit dont la troisième partie étudie la construction, en tant que mise en ordre du temps et de l'espace (Hérodote suit ou invente des manières de se repérer dans le temps; il arpente, compte, mesure, trace des itinéraires), en tant qu'héritier de riches traditions narratives, celles des Généalogies et des Périples notamment, enfin en tant que représentations du monde à partir de modèles cartographiques qu'il intègre à son outillage intellectuel pour donner à voir et à comprendre la répartition des peuples sur l'ensemble de la «terre habitée » dans la représentation d'un Grec. Les deux dernières parties étudient les questions du pouvoir, de la guerre et du politique. Rois, tyrans et cités confrontent leur manières de construire une autorité, de faire valoir des formes de "liberté ", de s'opposer à un ennemi. Dans ce jeu l'expérience des Barbares est tantôt restituée pour elle-même, tantôt utilisée pour définir l'identité des Grecs. La cinquième partie, une des plus riches, analyse la place des dieux et du divin, des pratiques et des rites religieux, dont l'importance est la même chez tous les peuples. C'est dans ce domaine que se manifeste certainement le mieux la singularité de la réflexion d'Hérodote, à la fois respectueux des croyances au point de paraître parfois crédule, et soucieux, à l'inverse, de marquer ses distances, pour lui-même et donc aussi pour ses auditeurs et lecteurs : «Libre à qui trouve de telles choses croyables d'accepter ces récits des Égyptiens; quant à moi, ce que je me propose tout au long de mon histoire est de mettre par écrit, comme je l'ai entendu, ce que disent les uns et les autres » (II, 123).

Chaque chapitre est pourvu d'une synthèse liminaire toujours éclairante et, en conclusion, d'indications bibliographiques récentes et précises. Des cartes et figures nombreuses permettent de se repérer dans le monde d'Hérodote et dans la représentation qu'il en donne. Une bibliographie finale, un lexique et un index contribuent à faire de ce livre la meilleure introduction à l'Enquête d'Hérodote et un précieux instrument de travail. Il est à souhaiter que la collection s'enrichisse d'autres titres pour mieux faire connaître l'historiographie grecque et latine et les renouvellements dont son analyse est l'objet.

\section{AUTEURS}

\section{PASCAL PAYEN}

Université de Toulouse II-Le Mirail

payen@univ-tlse2.fr 